\title{
Colour terms, kinship terms and numerals in Estonian Sign Language
}

\author{
Liivi Hollman
}

\section{Estonian Sign Language}

Estonian Sign Language (EVK) is a small language used by approximately 1,400-1,500 deaf people in Estonia, inhabited by 1.3 million people. EVK research only started in late 1980s and since 1994 EVK has also been used as a primary language in deaf education. Starting from $2007 \mathrm{EVK}$ is a legally recognised language in Estonia, enacted by the Language Act, which defines EVK as an independent language and signed Estonian as a mode of the Estonian language (Wheatley and Pabsch 2012: 55). Considering historical relationships, it may be assumed that EVK has probably been influenced by German and Russian traditions in deaf education and by Russian Sign Language, which, in turn, on the basis of historical knowledge, is believed to be connected to French Sign Language (LSF) and ASL (Zeshan 2005: 559).

The evolution of EVK is related to the establishment of the first deaf school in 1866 in Vändra, Estonia. Although, following the German tradition, oral teaching method was used in the school, signing in student communication was also supported. Therefore, bringing together deaf students from all over Estonia and giving them the possibility to communicate created a perfect environment for EVK to develop. During the Soviet era $(1940$ - 1991) deaf education was mostly influenced by the Russian tradition, and communication between deaf communities in Estonia and Russia, as well as other member states of the Soviet Union was strongly supported by mutual visits and co-operation. Together with the increase of the Russian population in Estonia in general, also the number of Russian deaf people living in Estonia increased. Although currently most of the Russian deaf children living in Estonia attend Estonian schools, it is estimated that based on the total number of Russian population in Estonia (340 000 people in 2012), there are approximately 300-400 Russian deaf people living in Estonia, being part of the Estonian deaf community but using also Russian SL.

A comparison of the EVK lexicon with the Russian SL lexicon, according to Swadesh's 200 -word list, shows that $61 \%$ of the signs are identical in these 
two languages (Taniroo 2007: 23), confirming the assumption that these languages are related somehow or there is some influence from Russian SL on EVK through language contact.

EVK in general as well as the EVK lexicon has not been widely studied. In the late 1980s and the beginning of 1990s, three small EVK dictionaries have been published (Toom 1988, 1990, and Kivisild and Toom 1990); they contain approximately 700 signs that form the basic vocabulary of EVK. Work with the online dictionary consisting about 5,000 signs is currently in progress. Besides some general overviews more specific descriptions have focused on noun phrases (Miljan 2000), adjectives (Miljan 2001), category of number (Miljan 2003); the system of personal name signs (Paales 2011), place names (Paales 2002) and colour terms (Hollman 2010).

In the current article three domains - colour terms, kinship terms and numerals in the EVK lexicon are described and the formation of the signs is analyzed.

\section{Colour terms in EVK}

The first survey on colour terms in EVK was carried out in 2005 (Hollman 2010). The research consisted of three tasks, following Davies and Corbett's field method (Davies and Corbett 1994: 69-72; 1995: 25-27; Davies, Corbett, and Margalef 1995: 22-26, Sutrop 2000, 147-148; 2002, 58). The first task was the list task where the subjects were asked to name as many colours as they could. Secondly, the subjects' ability to see colour was assessed using The City University Colour Vision Test (Fletcher: 1998). The answers from the respondents who failed the test were not included in the data analysis. The third task was the colour-naming task which involved showing the subjects 65 different colour squares in random sequence. The subjects were asked to name the colours of the tiles. After the three tasks were completed, a questionnaire about the background information (i.e. age, sex, place of residence and place of origin, education, schools attended, occupation, degree of deafness, hearing status of parents and siblings, access to sign language in the family before school or kindergarten started, and if there was no access to sign language in the family, the age when EVK was learned) of the subjects was filled out. A total of 50 deaf EVK users from different regions of Estonia were interviewed for the survey.

The subjects were contacted through the local deaf clubs and were selected from the two bigger cities having deaf schools and deaf clubs Tallinn and Tartu, the area of older and extant EVK - Pärnu, and Võru and Rakvere as small centres of the deaf where EVK is probably more influenced 
by spoken Estonian. The proportion of the subjects from these different regions followed the number of deaf people living in these areas. The group of subjects included 20 people from Tallinn, 11 from Tartu, 13 from Pärnu and 6 from Võru and Rakvere. There were 24 men and 26 women between the ages of 15 and 74 participating in the survey (Hollman 2010: 58-59).

The above mentioned colour terms survey revealed that EVK possesses a rich colour vocabulary. The list task data included 109 different colour signs, among them 19 simple colour names consisting from one sign only, excluding all the compounds and longer descriptions of colours and mentioned at least by four people in the study - two different names for red, signs BLUE, GREEN, YELLOW, BLACK, two different signs for white, a sign noted here as PINK/PURPLE, covering both lighter red area and the transition area of red and orange in the colour space, GRAY, BROWN, PURPLE, three signs for orange, BROWN/BEIGE, BEIGE, GOLD and SILVER. The data from the colour-naming task included 696 different terms including compounds and longer colour descriptions. In this task, more compounds were used (the average designation given to a colour tile being 1.79 signs) and only 225 signs out of 696 were mentioned at least twice. It may be seen from the data that when the subjects were asked to list the colours, they mainly used simple terms excluding compounds, but when asked to name 65 different colour tiles the number of compounds increased significantly in the data and the subjects also used longer descriptions to differentiate between colours, hues and shades.

According to the research data and considering the definition of a basic colour term by Berlin and Kay (1969: 6-7), who define basic term as

(1) a mono-lexemic term whose meaning is not predictable from the meaning of its parts; (2) a term whose signification is not included in that of any other colour term; (3) a term whose application is not restricted to a narrow class of objects and (4) a term which is psychologically salient for subjects (having a tendency to occur at the beginning of elicited lists of colour terms, and stability of references across subjects and across occasions of use and occurrence in the idiolects of all subjects);

it was concluded that EVK possesses nine basic colour terms - BLACK, WHITE, RED, YELLOW, GREEN, BLUE, GRAY, BROWN and PINK/PURPLE (Hollman 2010: 109). Corresponding to the criteria set by Berlin and Kay these terms were phonologically simple and their application was not restricted by the objects they describe. The salience of the terms used was analyzed using cognitive salience index (Sutrop 2001: 270, 273) which combines the tendency of a term to occur at the beginning of the lists (described by mean position of the term in the lists) and the occurrence in 
the idiolects of all subjects (described by total frequency). In addition to the terms having the basic status in EVK there is also a great variety of simple signs like - PURPLE, ORANGE and their variants, and different signs for white, red, brown etc. In contrast to PINK/PURPLE, the sign covering both pink and purple area of the colour space, PURPLE for example, not having a basic term status in EVK according to the survey because of its low frequency, appeared in the transition area of red and violet and violet and blue. There was also a great variety of signs used to denote orange: seven different signs were named more than twice in the list task and eight different signs in the colour-naming task, although most of them occurred only once for one tile. The number of different signs used to denote the basic colour categories and their most probable origins are shown in table 1.

Table 1. Number of EVK signs denoting the 11 colour categories and their motivation

\begin{tabular}{|c|c|c|}
\hline Colour category & $\begin{array}{l}\text { Number of } \\
\text { signs in EVK }\end{array}$ & Probable origin of the sign \\
\hline black & 1 & motivation from spoken Estonian \\
\hline white & 2 & $\begin{array}{l}\text { extension of the meaning, motivation } \\
\text { from pointing to representation of the } \\
\text { colour }\end{array}$ \\
\hline red & 2 & $\begin{array}{l}\text { motivation from pointing to } \\
\text { representation of the colour }\end{array}$ \\
\hline yellow & 1 & Russian SL loan \\
\hline blue & 1 & Russian SL loan \\
\hline green & 1 & extension of the meaning \\
\hline brown & 2 & $\begin{array}{l}\text { extension of the meaning, motivation } \\
\text { from pointing to representation of the } \\
\text { colour }\end{array}$ \\
\hline pink & 3 & $\begin{array}{l}\text { motivation from pointing to } \\
\text { representation of the colour, extension of } \\
\text { the meaning, initialisation }\end{array}$ \\
\hline purple & 6 & initialisation, loans, arbitrary signs \\
\hline beige & 3 & $\begin{array}{l}\text { initialisation, extension of the } \\
\text { meaning, motivation from pointing to } \\
\text { representation of the colour }\end{array}$ \\
\hline orange & 8 & initialisation, loans, arbitrary signs \\
\hline
\end{tabular}


Especially in the colour-naming task, also complex combinations of the colour signs occurred. The most frequent attributes used in sequential constructions to describe different colours were signs LIGHT, DARK, INTERMEDIATE, NORMAL (USUAL, REGULAR), BLEND, BRIGHT, but also many other attributes like VERY, PURE, WEAK, OLD, STRONG, GENTLE, SHARP, STRANGE, TIRED, FRESH etc were used in different combinations and in different order (see examples 1-4 below). The following examples are a random selection of compounds with different modifiers. According to the present data the modifiers are ordered flexibly - they either preceed or follow the colour sign or the colour sign is bracketed by the modifier while the word order does not influence the semantics of the compound. The order of the signs in the compound did not depend on either colour word or modifier.
(1) LIGHT BLUE light blue
(2) GREEN DARK dark green
(3) GREEN DARK GREEN dark green
(4) BRIGHT GREEN BRIGHT bright green

Comparison with objects typically having the respective colour may be used to describe the colours in more detail; comparison with the sky, sea, cherries, moss, strawberries, Estonian flag, forest, eggs, grass etc have occurred in the data of the colour terms survey (see examples 5-10 below).

(5) RED CHERRY SAME cherry

(6) YELLOW LEMON SAME

lemon yellow

(7) SPRUCE GREEN

green like spruce

(8) DARK CHOCOLATE BROWN

dark chocolate brown

(9) LIGHT BLUE SKY

light azure

(10) CARROT ORANGE LIGHT

light orange like carrot 
These descriptions are not considered as colour terms but different ways to describe colour in detail and therefore the descriptions may be quite long and complex (see examples 11-16).

(11) COLOUR PURPLE TOWARDS RED reddish purple

(12) PINK PLUS RED TOGETHER MIX DARK dark carnation red

(13) FRESH BLUE MIX WHITE ADD fresh whitish blue

(14) FRESH TRANSPARENT LIGHT GREEN fresh transparent light green

(15) INTERMEDIATE RED VIOLET WEAK slightly violet regular red

(16) LIGHT YELLOW ADD GREEN LIGHT light greenish-yellow

EVK possesses a generic term for colour derived from the sign PAINT. In some instances however a list of colours (RED+YELLOW+BLUE for instance) is used. Pointing to the colours in the surrounding environment in combination with the colour signs or generic sign for colour is possible but not conventionalised.

The most dominant (having the greatest frequency and occurring at the beginning of the elicited lists) simple colour sign according to the colour survey in EVK is BLACK (figure 1). The sign has two variants: it may be articulated with one upward movement or with a repeated movement. The most probable origin of the sign is the method used to help the deaf students feel the airflow while articulating nasal sounds by touching the nose with their finger as the Estonian counterpart must [black] starts with nasal $m$.

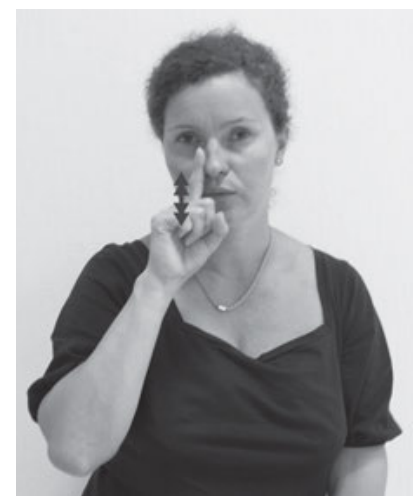

Figure 1. EVK colour signs: BLACK 
For white, there are two signs used in EVK. The more salient sign is formed on the back of the non-dominant hand with a forward movement by the dominant hand (figure 2a). It may be assumed that the formation of the sign is motivated by the white skin of the hands while the other sign for white, used with lower frequency according to the colour survey in EVK (figure 2b) is probably an extension of the meaning of the EVK sign CLEAN.

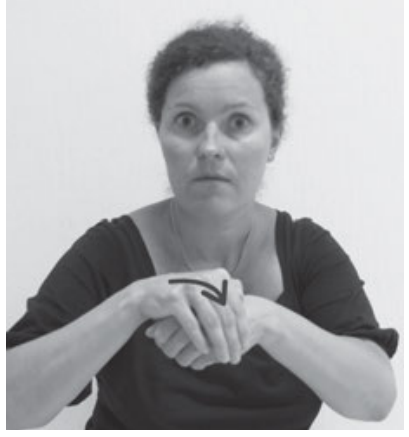

(a) WHITE 1

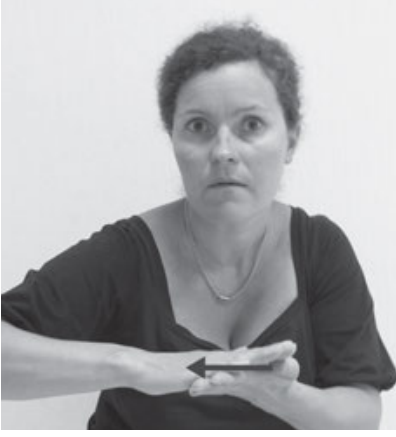

(b) WHITE 2 / CLEAN

Figure 2. EVK colour signs: WHITE 1, WHITE 2

It is interesting to note that while WHITE 2, identical to sign CLEAN, is mainly used by elderly subjects from one region in Estonia, WHITE 1 prevailed in the data given by younger subjects from different regions (figure 3 ), which leads to the assumption that the sign with the extension of the meaning is in all probability the older sign and is currently already disappearing from EVK.

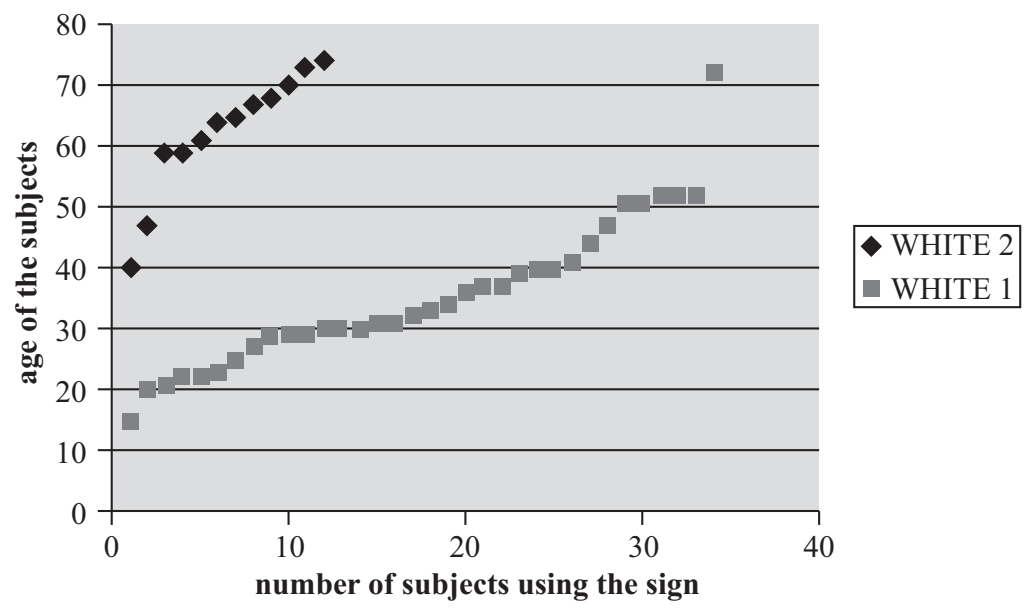

Figure 3. Age of the subjects using the signs WHITE 1 and WHITE 2 in the list task of the colour terms survey in EVK (Hollman 2010: 91) 
There are also two signs for red used in EVK. RED 1 is articulated with a round movement on the cheek (figure $4 \mathrm{a}$ ) probably motivated by a blushing face. The sign is very similar to the sign PINK (VAALEAPUNAINEN [PINK]) in Finnish Sign Language. There has been no considerable historical language contact between EVK and Finnish Sign Language although the two spoken languages (Estonian and Finnish) are very similar Finno-Ugric languages. Therefore, it is difficult to decide weather RED 1 is just motivated from pointing or it is a loan from Finnish SL. The other sign for red (figure 4b), articulated on the lips with the index finger, is similar to the sign RED in many other sign languages, including Russian SL and ASL, and is probably derived from pointing to the lips, typically representing the red colour, although in EVK it is difficult to say if it is derived from pointing or if it is an influence from other sign languages, for example from Russian SL.

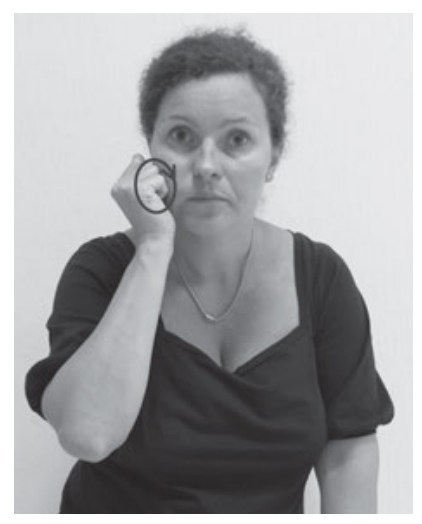

(a) RED 1

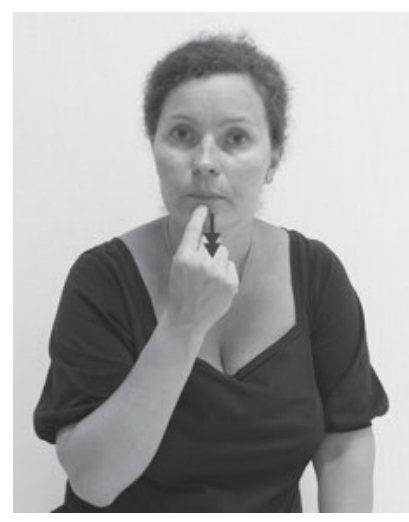

(b) RED 2

Figure 4. EVK colour signs: RED 1, RED 2

RED 2 is however quite rare in EVK; according to the data of the colour term survey the sign was used mainly by the elderly subjects, prevailing in the lists of subjects from deaf signing families, while RED 1 was used by the subjects from the hearing families, suggesting that RED 1, either a loan or a native EVK sign, is now fully lexicalised while RED 2 seems to be disappearing. The same sign RED 2 accompanied by a different mouth pattern is also used to denote both wine and ruby. According to the explanations by the EVK users, the infrequency of RED 2 might also be related to the fact that the use of the two signs for red is dependent on the object described and the sign RED 2 would most likely be used for fluids like wine, juice or blood.

GREEN is articulated in three different variants: with an upward arc movement in neutral space (GREEN a, figure 5a), a two-handed sign formed 
with a divisive downward movement (GREEN b, figure $5 b$ ) or with a divisive downward movement in front of the face (GREEN c, figure 5c). A wiggling movement of the fingers is also characteristic of the sign in all its variants.

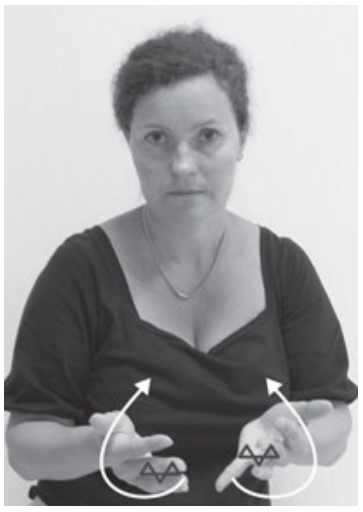

(a) GREEN a

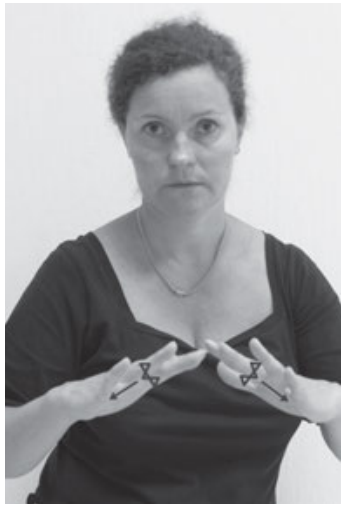

(b) GREEN b

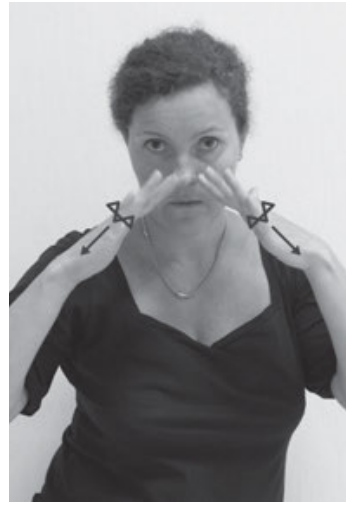

(c) GREEN c

Figure 5. EVK colour signs: three variants of the sign GREEN

In the EVK colour terms survey GREEN a was mostly used by the elderly subjects while GREEN $b$ and GREEN $c$ were used by the younger subjects (see figure 39 for the age distribution of the subjects using different variants of the sign GREEN).

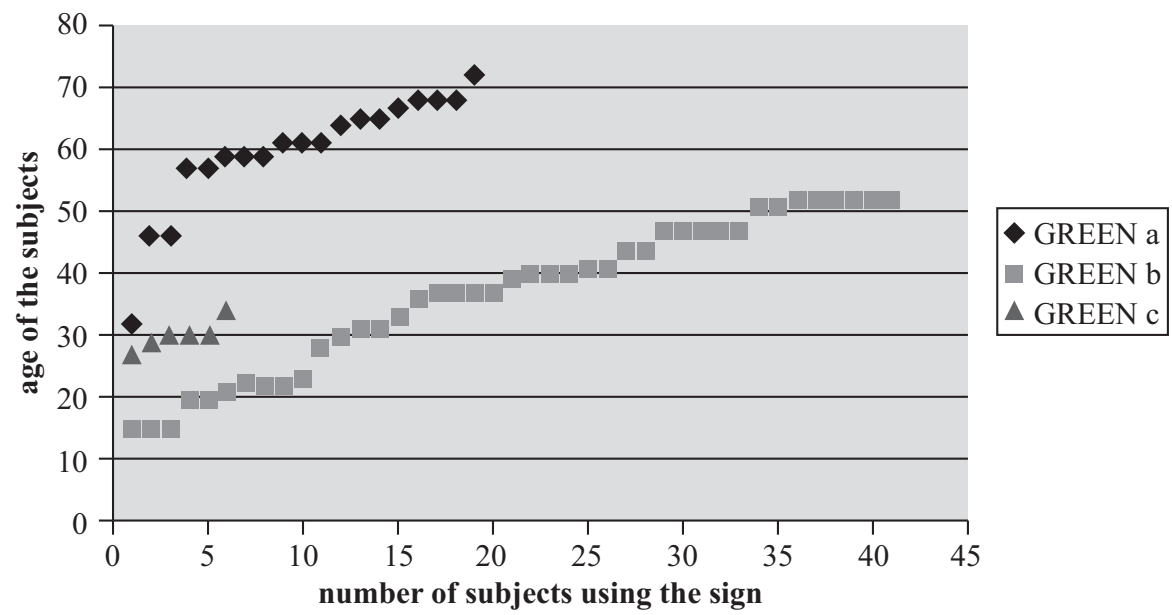

Figure 6. Age of the subjects using GREEN a, GREEN $\mathrm{b}$ and GREEN $\mathrm{c}$ in the list task of the colour terms survey in EVK (Hollman 2010: 95) 
As the oldest variants of the sign are probably two-handed signs articulated in neutral space, either with an upward arc movement (figure 5a), or a divisive downward movement (figure 5b), the first identical to the sign CHRISTMAS, and the second similar to the sign SPRUCE (formed by repeated downward movement, no wiggling of the fingers), it may be assumed that the sign is motivated by the green Christmas tree. The location of the sign has moved up diachronically. The newest variant is signed in front of the face and is becoming a one-handed sign.

A comparison of the EVK lexicon to Russian SL, according to Swadesh's list mentioned above, also includes some colour terms. The study describes five colour terms - black, white, red, green and yellow. According to Taniroo (2007: 23), only the sign YELLOW (figure 7) is identical in both sign languages. There are no studies of comparing EVK vocabulary with any other sign languages than Russian SL.

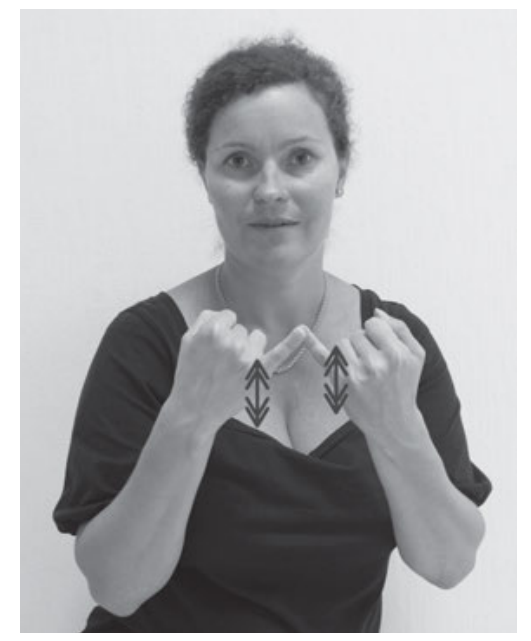

Figure 7. EVK colour signs: YELLOW

In the Estonian context, the sign seems to be arbitrary, with no clear motivation or initialisation but, considering the obvious influence from Russian SL or even an implicit influence from French SL and ASL, EVK YELLOW may have originated from an initialised sign (the $\mathrm{Y}$ handshape from the English yellow or $\mathrm{J}$ handshape from the French jaune [yellow]). Although ASL YELLOW is a one-handed sign, in EVK and Russian SL the sign is definitely formed by two hands. It might be assumed that EVK YELLOW, of Russian, American or French provenance, has moved from its original location to a more central location and, characteristic of a sign formed in front of the body, has become a two-handed sign. 
The EVK sign BLUE (figure 8) is also identical to the respective sign in Russian SL and is probably also a loan from Russian SL. BLUE is articulated either in the neutral space or in front of the face.

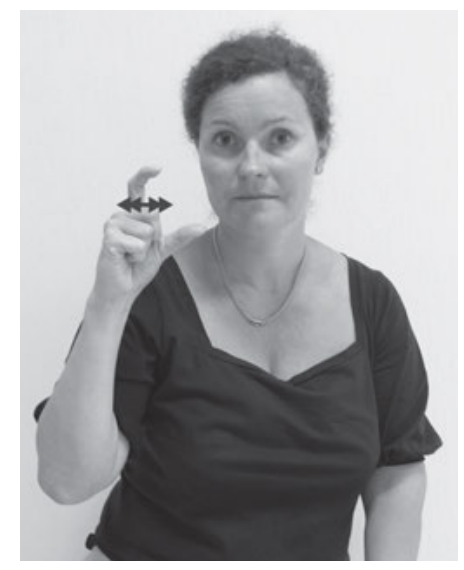

Figure 8. EVK colour signs: BLUE

GRAY (figure 9) is also very clearly a basic colour term in EVK, being in all probability a native sign, very salient and practically the only sign for gray in EVK. Similarly to the sign BLACK, it may be articulated with a single movement or in a reduplicated form.

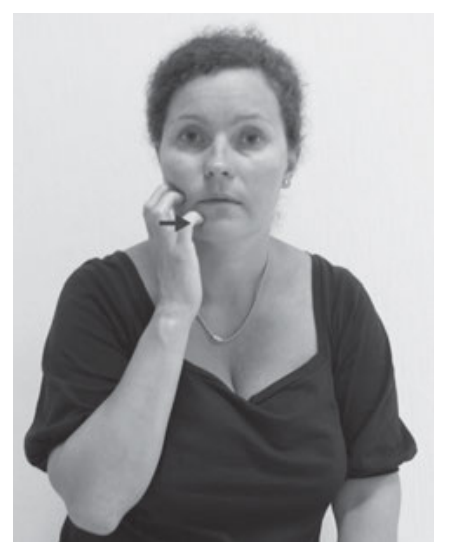

Figure 9. EVK colour signs: GRAY

The EVK sign for pink and purple, here glossed as PINK/PURPLE, is also probably motivated by a blush, similarly to RED 1, the sign is articulated in many different ways: with wiggling fingers and the palm oriented either towards or away from the signer, and with still fingers and the palm oriented 
either towards or away from the signer (figure 10). In some cases, the sign is even articulated in neutral space, not on the cheek.
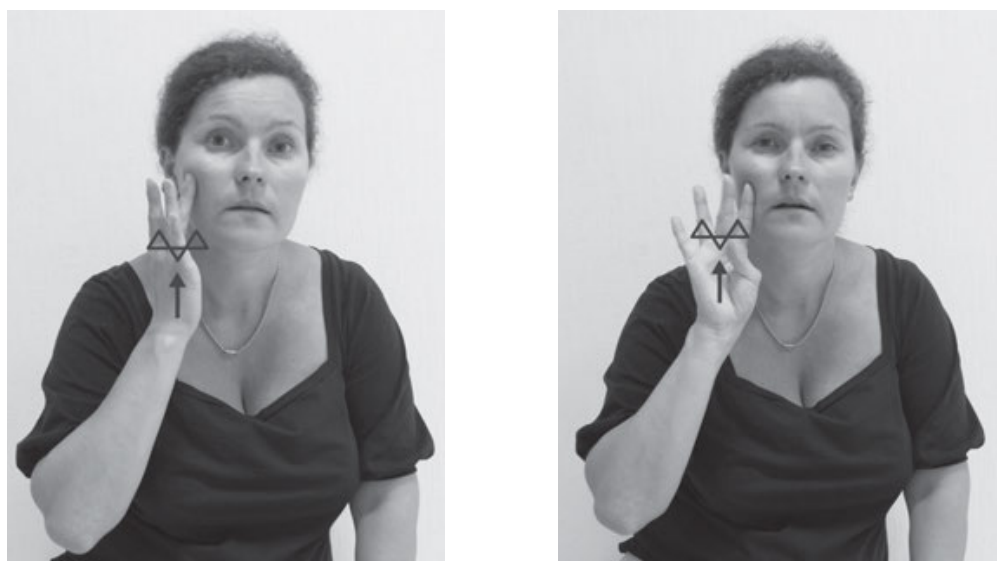

Figure 10. EVK colour signs: different variants of the sign PINK/PURPLE denoting the composite category of pink and purple

BROWN (figure 11) is probably derived from an extension of the meaning of the sign COFFEE. BROWN is articulated with two hands touching each other, while the sign COFFEE is formed with a larger movement and with no contact between the two signing hands.

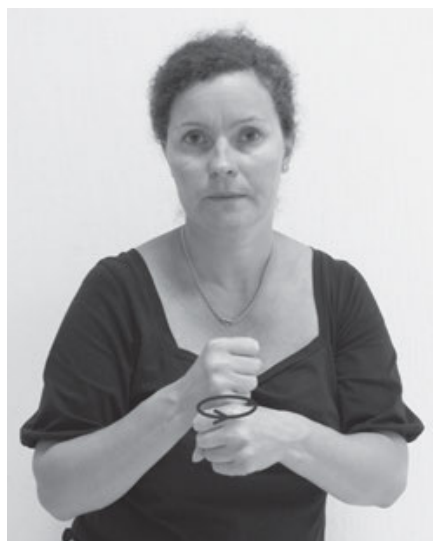

Figure 11. EVK colour signs: BROWN

The sign for coffee is obviously motivated by the movement of coffeegrinding, but it is difficult to determine if the extension of the meaning of the colour brown was developed in EVK or if it is a loan or influence from another sign language having the same sign for coffee. 
The most salient EVK sign for orange (figure 12a), as well as signs PURPLE (figure 12b) and BEIGE (figure 12c) are initialised signs articulated with the handshape of the first letter of the respective colour word in Estonian. The sign ORANGE is formed with the EVK O handshape (figure 12d) from the Estonian word oranž for orange. PURPLE is articulated with the same movement and in the same location, but with the L handshape (figure 12e) from the Estonian word lilla for purple, and BEIGE is articulated with a B handshape (figure 12f) from the Estonian word beež for beige.

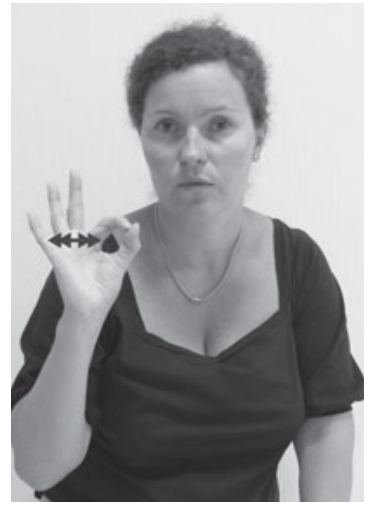

(a) ORANGE

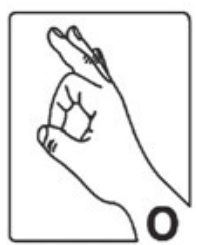

(d)

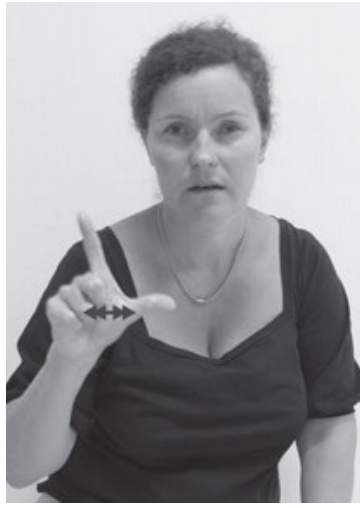

(b) PURPLE

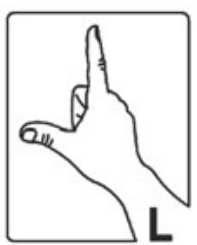

(e)

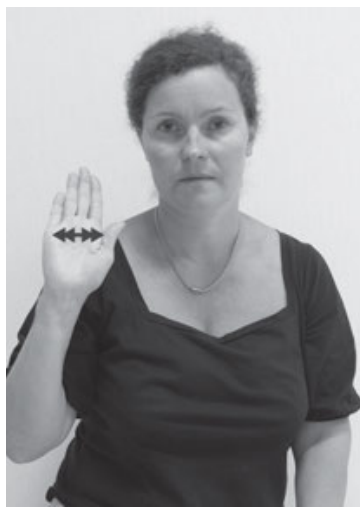

(c) BEIGE

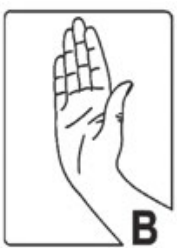

(f)

Figure 12. EVK colour signs: ORANGE, PURPLE and BEIGE

Due to the fact that the oral teaching method prevailed in Estonia for a long time, signed Estonian is also used in the Estonian deaf community, especially among older generation, and the influence from spoken Estonian may be observed both in EVK vocabulary and grammar. Estonian and signed Estonian is also used to describe colours. Estonian colour words may be used alone or they may be accompanied by the respective EVK colour sign. Sometimes a certain mouth pattern is used to distinguish the meaning of the signs referring to different colours, as the above mentioned sign PINK/ PURPLE. The sign may therefore be accompanied by the mouth pattern 
roosa [pink] for pink, or lilla [purple] for purple. Although different mouth patterns are used, PINK/PURPLE accompanied with different mouth patterns does not constitute separate lexicalised signs in EVK. To cover the transition area of red and violet, an initialised sign PURPLE is used although it doesn't have basic colour term status in EVK yet. Fingerspelling Estonian colour words may also be used although there are no lexicalised fingerspelled signs among the colour signs in EVK.

Using the methodology and research materials of the Sign Language Typology project of the International Institute for Sign Languages and Deaf Studies (University of Central Lancashire) for the data collection, besides basic colour signs and numerous compounds and longer descriptions, a wide variety of manual (speed, intensity, direction of the movement, reduplication) and non-manual (squint or raised eyebrows, head and body movements) markers used to compare different levels of darkness, lightness and saturation was also revealed. These features only become evident through the dialogues used in the latter study.

To express the quality of darkness and lightness, in EVK signs for light and dark may be used. These signs can be inflected to refer to the degree of lightness or darkness by the extent and intensity of the movement and nonmanual markers.

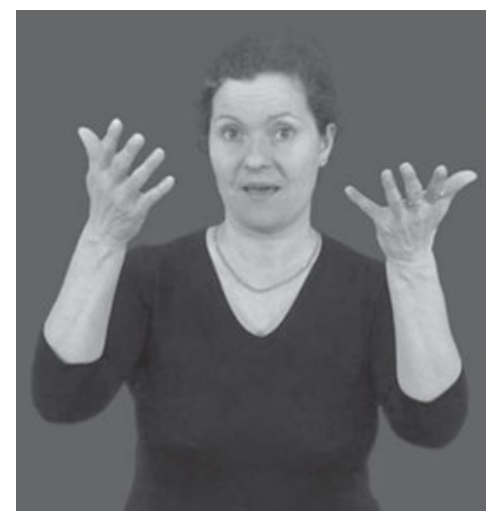

(a) LIGHT

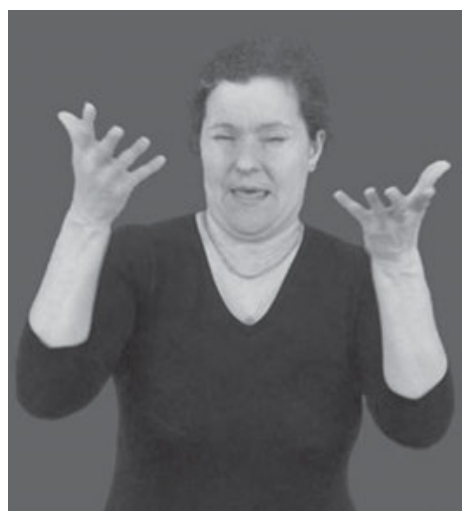

(b) VERY_LIGHT

Figure 13. Non-manual marking of the sign LIGHT in EVK

Raised eyebrows, head and body moving backwards accompany the signs to refer to lighter shades (figure 13) while furrowed eyebrows, narrowed or even closed eyes, head and body moving forward mark the signs for darker shades (figure 14). 


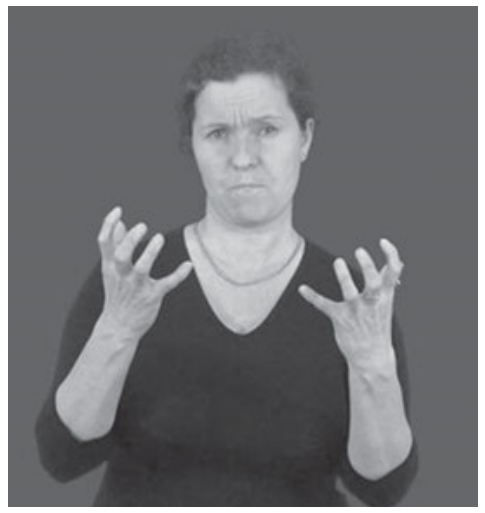

(a) DARK

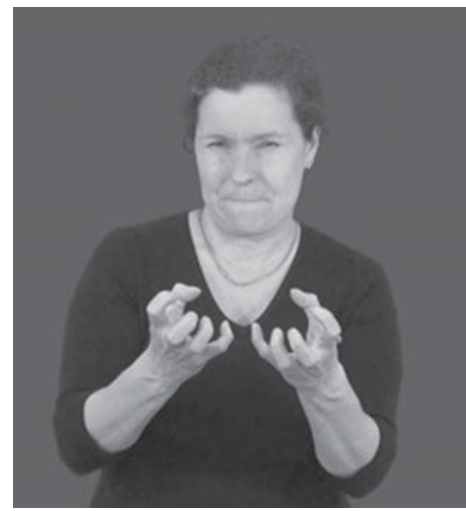

(b) VERY DARK

Figure 14. Non-manual marking of the sign DARK in EVK

The colour signs may also be modified by reduplication and the amplitude and intensity of the movement to express the extent of saturation. A reduplicated sign formed with a slighter movement may refer to a less saturated hue of a colour while a single and more intensive movement is used to denote pure and deep hues of the same colour. A slight repeated movement in articulation of the sign GRAY (figure 15a) referres to grayish hue and the intensive single movement to pure gray (figure 9).

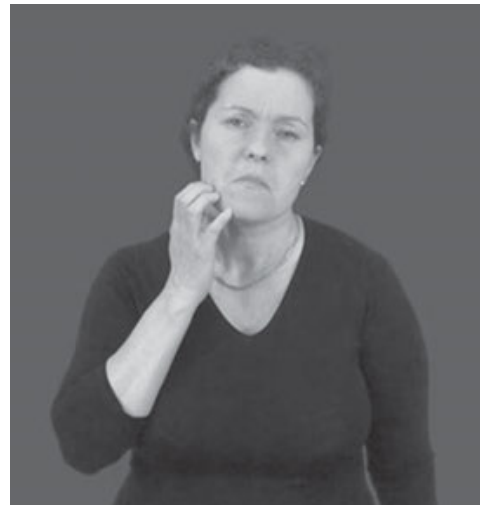

(a) GRAY/GRAYISH

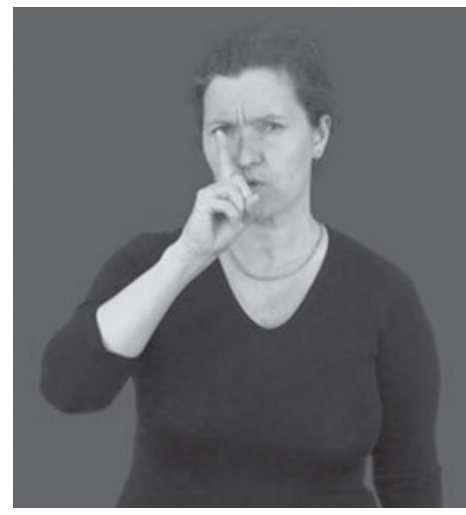

(b) BLACK/DEEP_BLACK

Figure 15. Manual marking of the colour signs in EVK

The same principle may be seen in the articulation of the sign black referring to either blakish shades or deep black (figure 15b). 
Non-manual markers (raised shoulders, squint or raised eyebrows, narrowed or closed eyes) also mark colour signs to refer to the extent of saturation (figure 16).

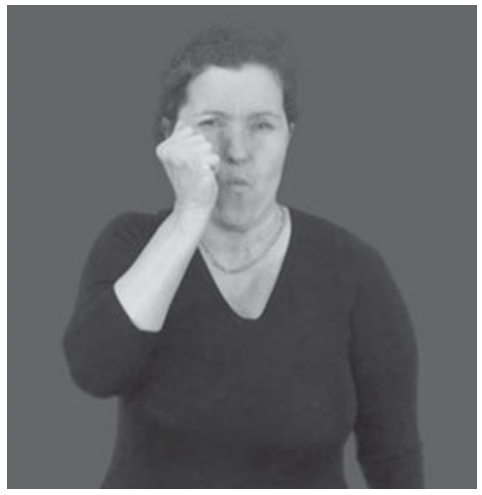

(a) DEEP RED

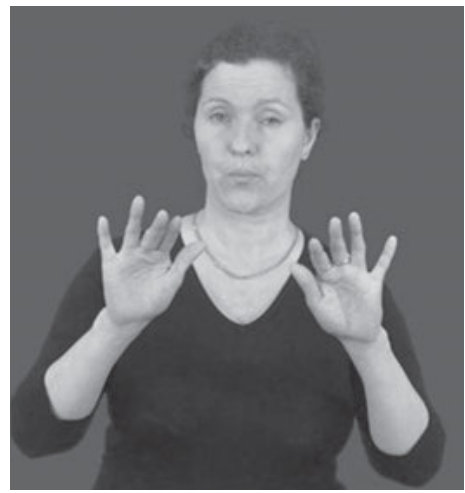

(b) GREENISH

Figure 16. Non-manual marking of the colour signs EVK

Raised shoulders, furrowed eyebrows and narrowed eyes refer to more saturated and darker hues (figure 16a) while raised eyebrows denote less saturated and lighter hues (figure 16b). Other markers like pursed lips may also be observed to express saturation and darkness.

Research about the colour terms in Estonian (Sutrop 2002) shows that there are 11 basic colour terms in Estonian. Comparing colour terms in EVK with the colour vocabulary in the Estonian language it may be seen that although the number of basic terms is EVK is smaller and the colour vocabulary is not as rich as in Estonian, the same colour categories are still covered by simple colour signs.

As seen in table 1, there are only one or two signs used to denote colour categories higher in Berlin and Kay's colour terms hierarchy (Berlin and Kay 1969: 15) while the number of terms usually emerging in a language later in its development is quite high and the terms have not yet become basic in EVK.

\section{Numerals in EVK}

The numerals were collected using the methodology and research materials of the Sign Language Typology project of the International Institute for Sign Languages and Deaf Studies (University of Central Lancashire). Two different games were used for data collection. In the first game two 
EVK signers participating in the study were asked to choose five objects with considerable value and five objects with a small value. One of the players was a seller and the other one was a buyer. The buyer was asked to bargain with the seller to buy the products. In the second game the subjects had a set of 40 cards with arithmetic instructions. The two participants took turns to take a card from the desk, sign the arithmetic instruction on it as well as the result. Both games were video recorded.

The cardinal numerals $0-10$ are highly iconic in EVK, as is characteristic in many sign languages. The iconic base of the numeral signs for $1-5$ is the number of extended fingers, and of the signs for 6-9, the sum of 5 fingers of the nondominant hand and 1-4 fingers of the other hand producing the sign. Numeral signs 1-5 are therefore one-handed representations of the numbers expressed by the respective number of extended fingers, starting with the index finger, while the sign for zero is a representation of the shape of the digit 0 (figure 17, a-f).

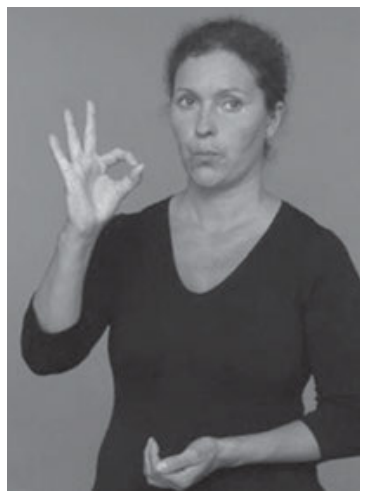

(a) ZERO

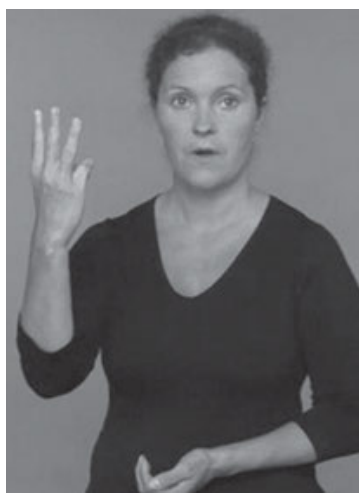

(d) THREE

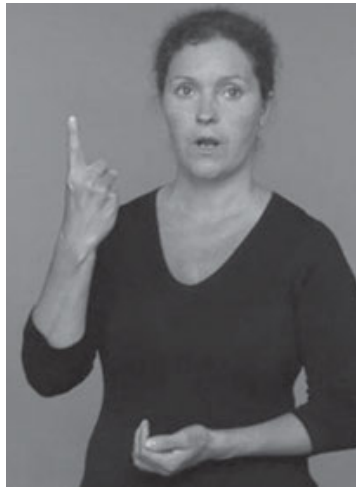

(b) ONE

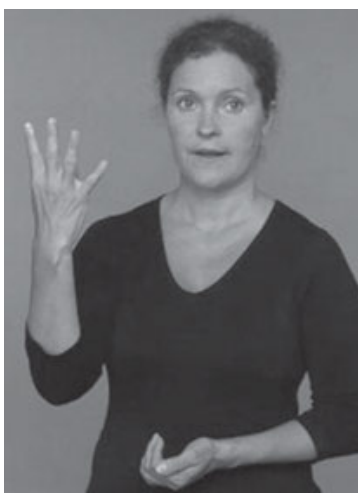

(e) FOUR

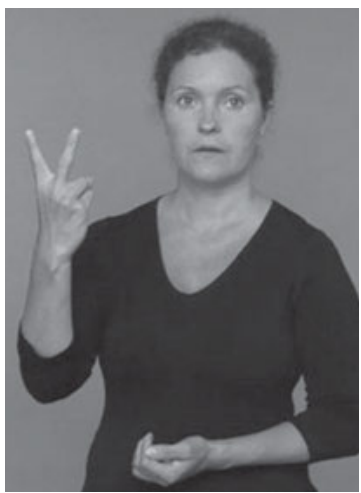

(c) TWO

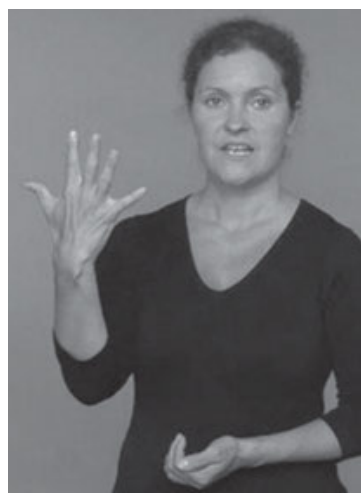

(f) FIVE

Figure 17. Numeral signs $0-5$ in EVK 
The signs for 6-9 have originally been two-handed and were formed either on the palm of or alongside with the non-dominant hand with 1-4 extended fingers respectively, starting with the thumb (figure 18). The fact that numbers 1-5 and 6-9 are formed with different fingers extended has allowed these signs to change into one-handed signs which tend to be more widespread in the usage of younger signers. This tendency has also been a reason for variation of the sign for three, originally formed with the same handshape as EIGHT (figure 18c), but now changing to w-handshape (figure 17d) to allow clear distinction between numerals THREE and EIGHT signed with one hand only; and the sign for nine, signed with the same handshape as FOUR (figure 18d) in a two-handed sign and with the different handshape (figure 18e) in a one-handed sign.

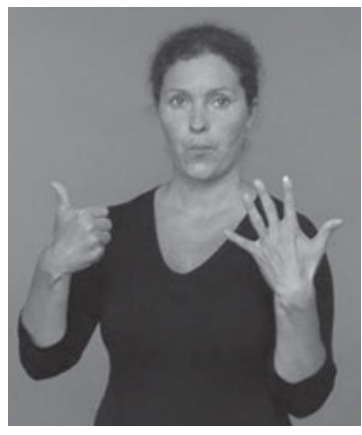

(a) SIX

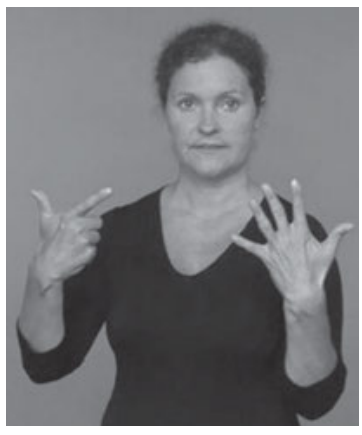

(b) SEVEN

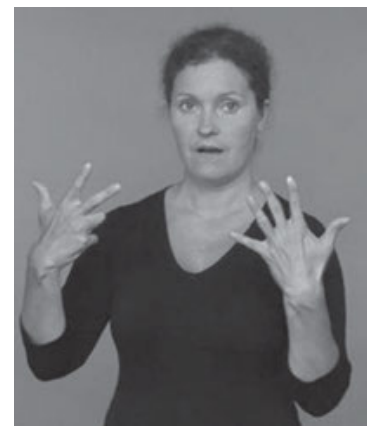

(c) EIGHT

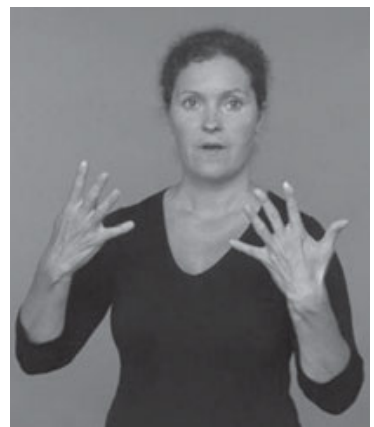

(d) NINE a

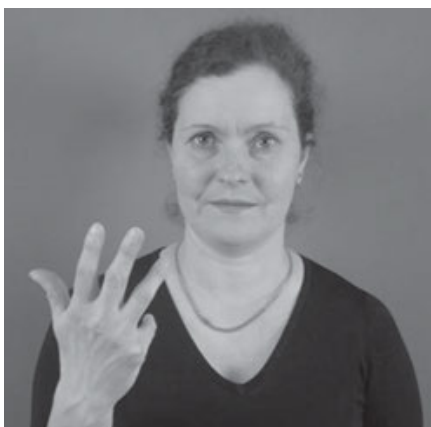

(e) NINE b

Figure 18. Numeral signs 6-9 in EVK

The main strategy for expressing complex numbers above ten in EVK is to combine a single digit sign with a certain movement pattern. Numerals 11-15 are formed by the same handshape as numerals for $1-5$ with repeated turning movement from the wrist (figure 19a) and multiples of ten are formed with the repeated movement from side to side (figure 19b). The numerals for 
16-19 are more complicated, formed on the palm of the non-dominant hand as signs SIX, SEVEN, EIGHT and NINE but with an opening downward movement (figure 19c). Sequential compounds of multiples with ten are sometimes also used, but it seems to be rather an influence from other sign languages and International Sign than a construction characteristic of EVK. In educational settings often simultaneous compounds of the sign ONE formed by the nondominant hand and numeral signs for 1-9 formed by the dominant hand with a turning movement from the wrist to represent numerals 11-19 and their written form simultaneously may be observed.

The sequential compounds are also used to express complex numbers above twenty. These numerals are signed with the iconic handshape of the respective number combined with a certain movement pattern while signing follows the written form of the number - the multiples of thousands, hundreds and tens are signed from left to right as in the written form of a certain number. Therefore, while forty-seven is produced by 4 handshape with repeated movement from side to side followed by the sign SEVEN next to the sign FORTY (figure 19d), the sign seventy-four starts with sign SEVENTY on the left followed by the sign FOUR moving a little right next to the previous sign.

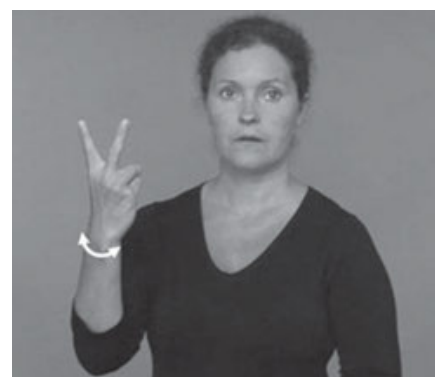

(a) TWELVE

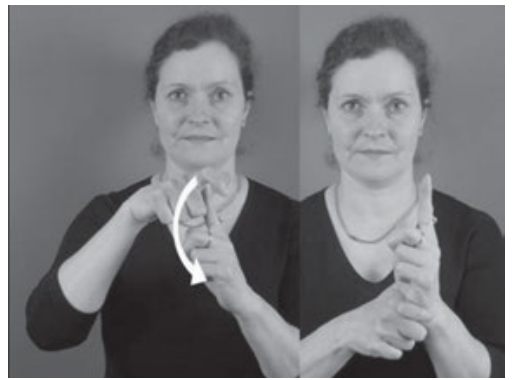

(c) SEVENTEEN

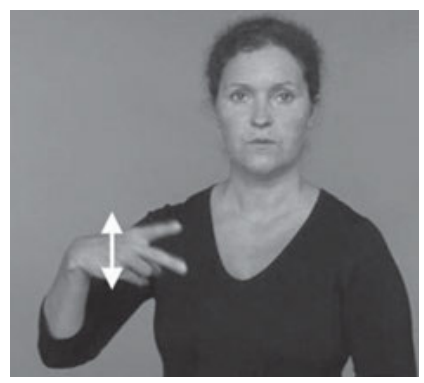

(b) TWENTY

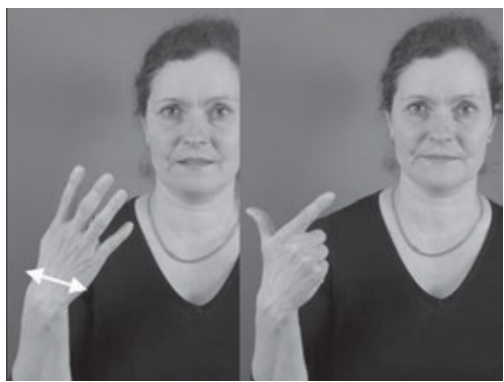

(d) FORTY-SEVEN

Figure 19. Numeral signs TWELVE, TWENTY, SEVENTEEN and FORTY-SEVEN in $\mathrm{EVK}$ 
EVK possesses lexical signs HUNDRED (figure 20a), thousand (figure 20c), million (figure 21a) and billion (figure 21b). TEN+THOUSAND and HUNDRED + THOUSAND as well as TEN+MILLION are sequential compounds of the respective signs TEN, HUNDRED, THOUSAND and MILLION similarly to the respective compounds used in spoken Estonian.

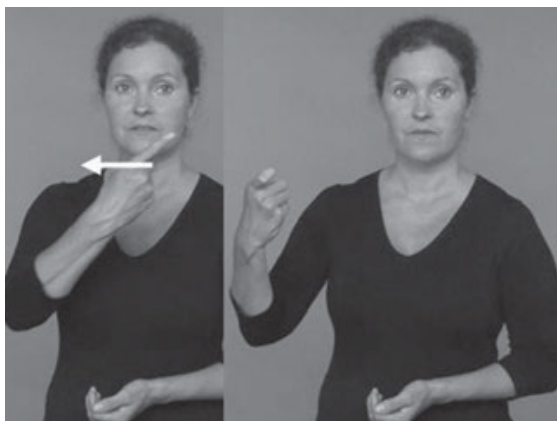

(a) HUNDRED

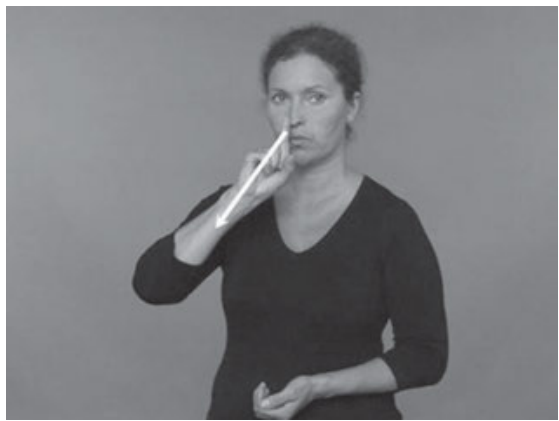

(c) THOUSAND

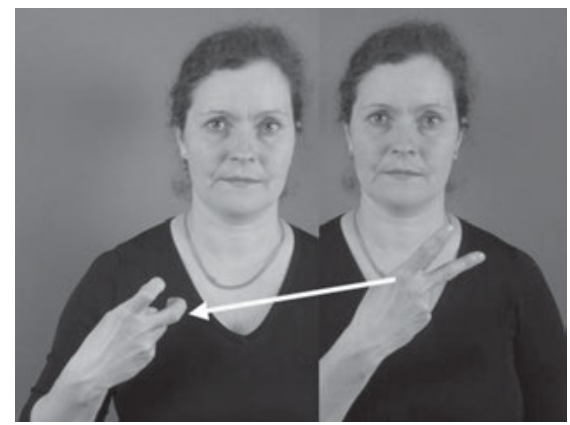

(b) TWO_HUNDRED

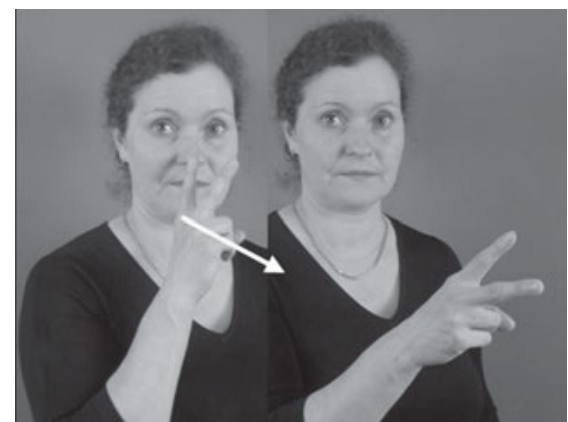

(d) TWO_THOUSAND

Figure 20. Numeral signs HUNDRED and THOUSAND and incorporated signs TWO_HUNDRED and TWO_THOUSAND in EVK

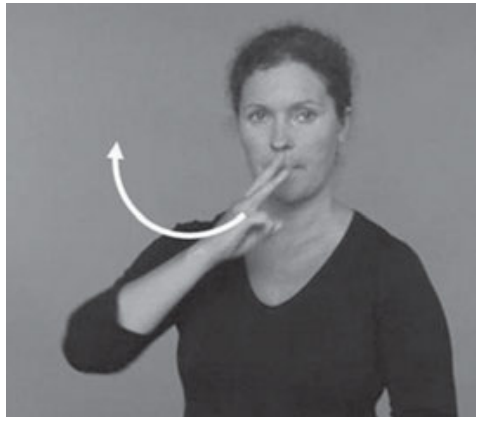

(a) MILLION

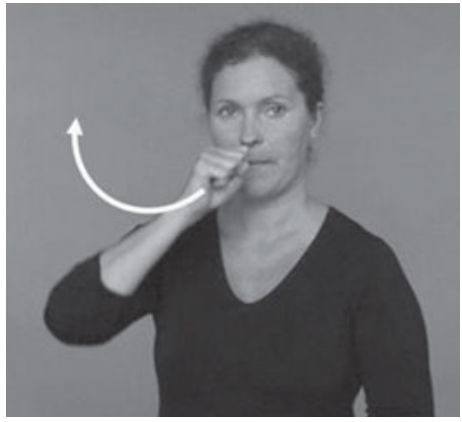

(b) BILLION

Figure 21. Numeral signs MILLION and BILLION in EVK 
Multiples of hundred and thousand are expressed by numeral incorporation with the signs HUNDRED and THOUSAND (figure 20b and 20d). Numeral incorporation is also used for time units (year, month, week, and hour) as well as for classifiers (people, floors). All these signs are formed with the extended index fingers in their original form, easily allowing numeral incorporation.

There are several strategies used to express fractions in ESL. Cutting off movement with the thumb on the second finger is used to represent one and a half. The sign may be used in different contexts referring to different quantities - time, volume, weight, length etc (figure 22a) and the same sign produced on the third or little finger is also possible although not conventionalised in EVK. Other strategies involve compounds with the signs PERCENT (figure 22d) HALF (figure 22b) or QUARTER (figure 22c). The latter however is strongly related to the sign HOUR and although sometimes also used in other contexts, mainly related to time units only.

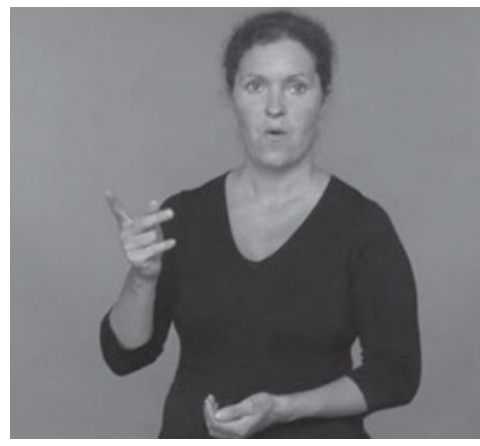

(a) ONE_AND_A_HALF

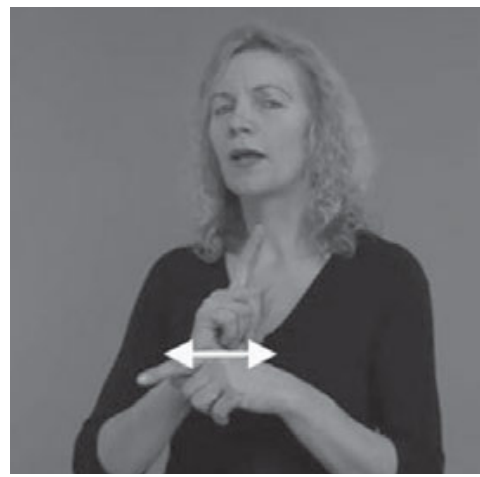

(c) QUARTER

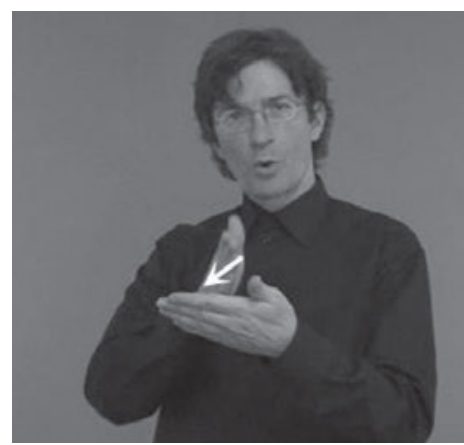

(b) HALF

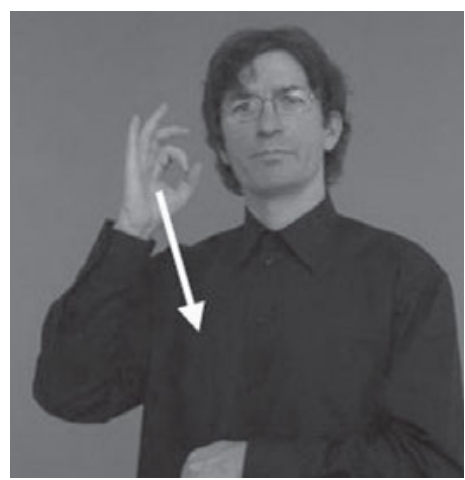

(d) PERCENT

Figure 22. Fractions in ESL: ONE_AND_A_HALF, HALF, QUARTER and PERCENT 
The most common way to indicate fractions is representation of their written form by using numerals in sequential compounds with the sign POINT or by indication of the columnar difference, forming the sign for numerator higher in the signing space and the denominator signed below it (figure 23).

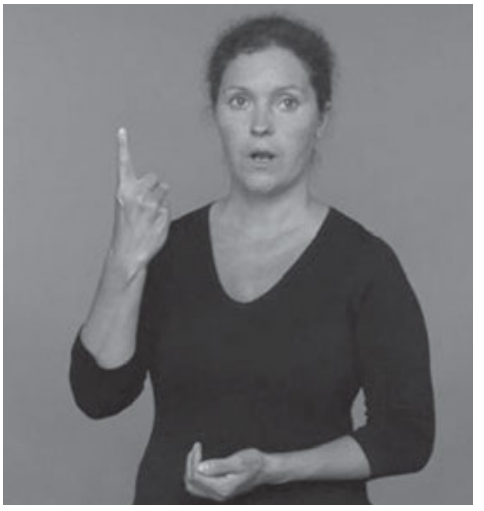

ONE

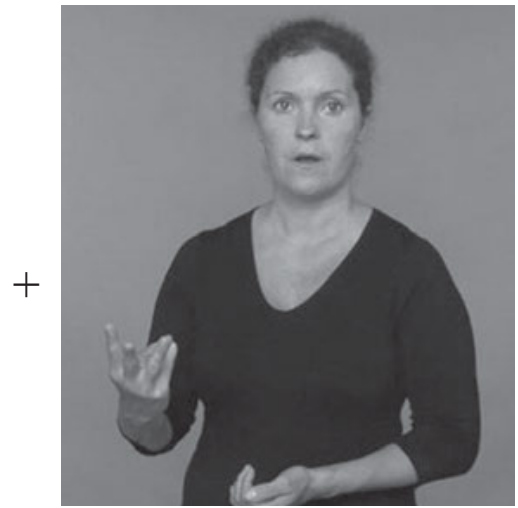

THIRD

Figure 23. Fractions in ESL: ONE+THIRD

The ordinal numerals are derived from cardinal numerals with a certain movement pattern similarly to numerals above ten. The movement pattern applied is a single turn from the wrist with the hand slightly moving upward (figure 24a). Also pointing to the respective finger of the non-dominant hand is used for ordinal numerals. Both strategies are only productive for numerals up to ten.

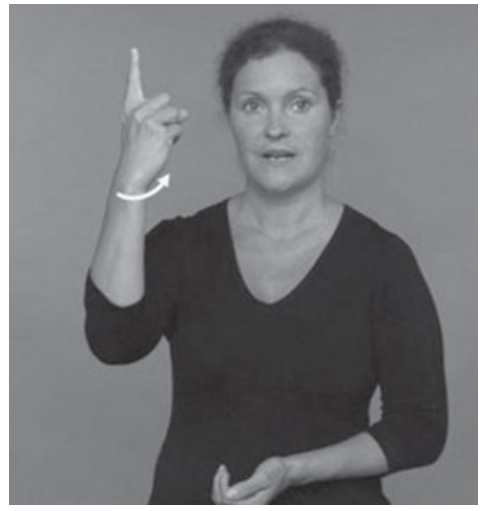

(a) FIRST

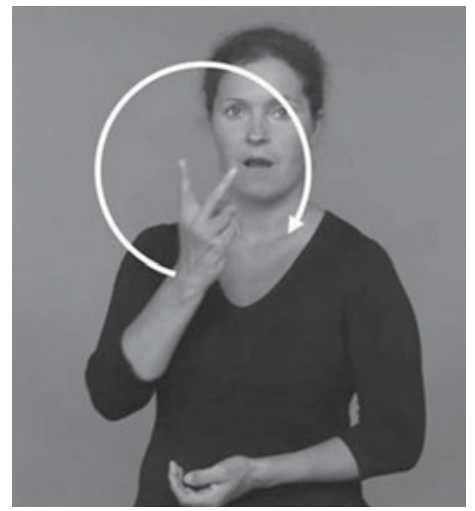

(b) TWO YEAR

Figure 24. EVK ordinal numerals and plural marking: FIRST and TWO_YEAR 
Plural marking in EVK is realised in several different ways. Besides numerals, EVK possesses a set of lexical quantifiers like ALL, EVERY/EACH, MANY, SOME, FEW, NO, NONE, NOTHING etc which can be used to express quantities. As stated above, many signs (YEAR, MONTH, WEEK and HOUR) and classifiers, also allow numeral incorporation to express dual, trial, quadruple and quintuple (figure $24 b$ ).

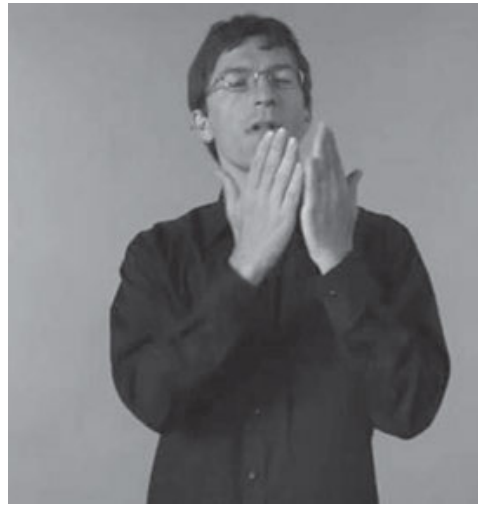

BOOK

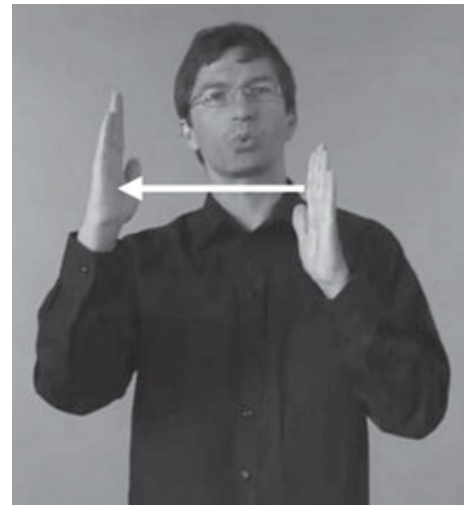

classifier tracing

Figure 25. Plural marking in EVK: reduplication of classifiers

Thirdly, reduplication of the sign or classifier may be used. The reduplication may be individually articulated repetition of a sign (SIBLING+++, CHILD +++ , PERSON +++ ) in different locations, reduplication of a classifier combined with the locational modification or a tracing movement (books, figure 25). Reduplication and spatial inflection is also applicable to some quantifiers.

As seen from the analyses above the numerals in EVK are formed by iconic handshapes representing the number, with movement patterns related to numeral series and multiples. The location of the sign may also follow the written form as in fractions and complex numbers.

\section{Kinship terms in ESL}

The kinship terms were also collected using the methodology and research materials of the Sign Language Typology project of the International Institute for Sign Languages and Deaf Studies (University of Central Lancashire). Two games were used for data collection. In the first game two EVK signers participating in the study were asked to discuss and provide a list of family 
members that would be invited to a wedding. The second game included a family tree chart. The player having a chart had to ask questions from another player to get to know his/her family members to fill in the chart. The game was repeated changing the roles of the players. All the discussions were video recorded for the further analyses.

EVK uses both lexicalised signs as well as pointing in the signing space to express kinship terminology and family relations.

EVK possesses simple gendered terms for man, woman, girl, boy, mother, father, son and daughter and simple non-gendered terms for spouse, siblings, parents'siblings, fiancé/fiancée and cousin. Gender distinction in the signs SPOUSE, SIBLING and RELATIVE is secondary and is performed by attributive signs MAN, WOMAN, BOY and GIRL.

Generic kinship terms are either simple lexicalised signs (CHILD, SPOUSE, SIBLING, RELATIVE) or lexicalised lists of the members of the group (MOTHER+FATHER). More specific terms are either simple lexicalised signs (GIRL, BOY, MOTHER, FATHER, DAUGHTER, SON), lexicalised sequential compounds $(\mathrm{BOY}+$ SIBLING, GIRL+SIBLING, FEMALE+RELATIVE for aunt, MALE + RELATIVE for uncle, OLD + FATHER for grandfather and, OLD + MOTHER for grandmother) or complex combinations describing the family relations (SPOUSE OWN GIRL+SIBLING for sister-in-law).

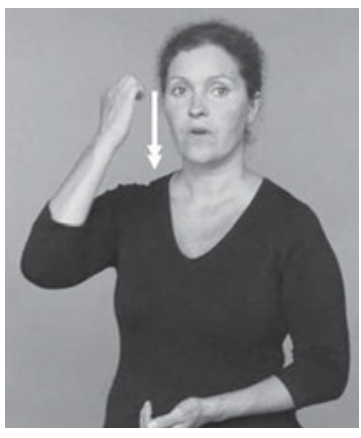

(a) PARENTS

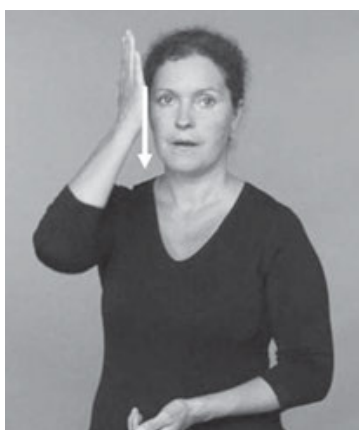

(b) MOTHER

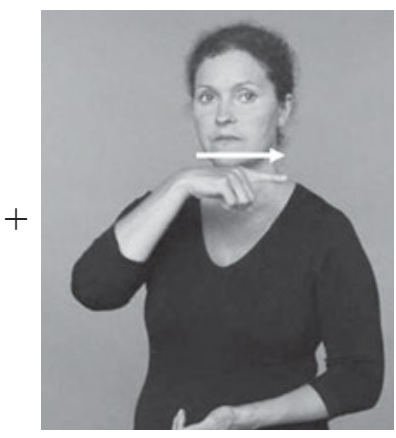

(c) FATHER

Figure 26. EVK core family terms: PARENTS, MOTHER+FATHER, MOTHER and FATHER

The generic non-gendered term PARENTS (figure 26a) is a calque from spoken Estonian and not as frequent as the sequential compound MOTHER +FATHER (figure 26b+c). In spoken Estonian the term is derived from the word vana (old, older) - and the EVK counterpart is an exact translation of the term, using the reduplicated sign $\mathrm{OLD}^{+++}$. Other core family terms like MOTHER (figure 26b), FATHER (figure 26c), DAUGHTER (figure 27a) 
and SON (figure 27b) are gendered terms; only the main sign for siblings (figure 27c) does not differentiate gender. Not all the core kinship terms are phonologically distinct from each other. While MOTHER, FATHER, BOY and GIRL do not seem to share any common features, DAUGHTER and SON are formed with the same movement in the same location to indicate birth but with a different handshape. The shared handshape in MOTHER, DAUGHTER and GIRL is probably a co-incidence only.

The gender distinction is only possible by using the attributive signs BOY+SIBLING (figure 27d) or GIRL+SIBLING (figure 27e). These compounds are quite frequent to mark the gender. Gender marking may also be indicated by mouthing.

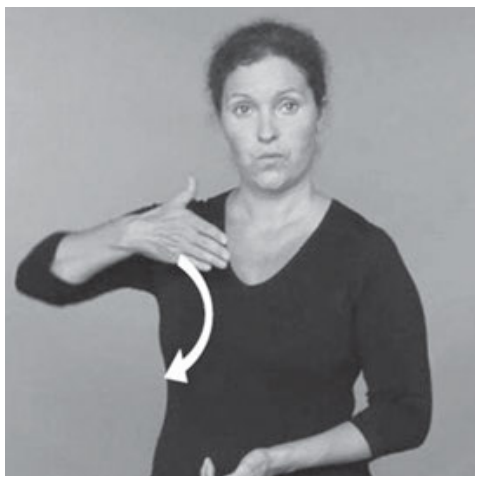

(a) DAUGHTER

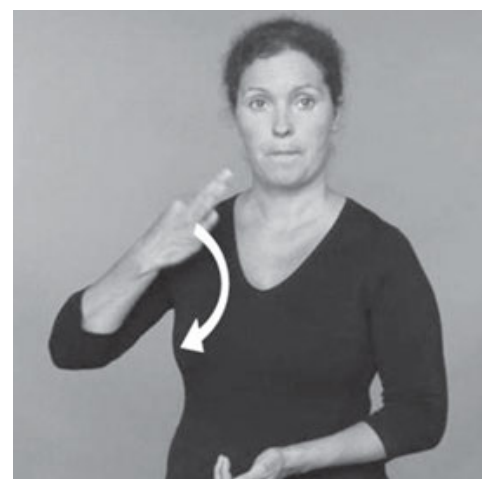

(b) $\mathrm{SON}$

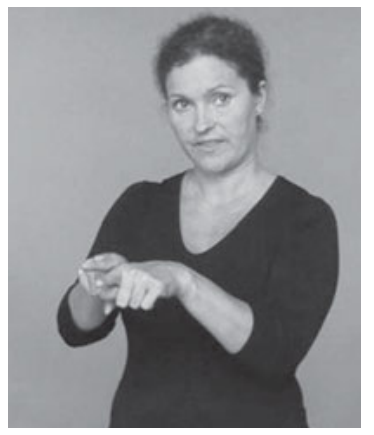

(c) SIBLING

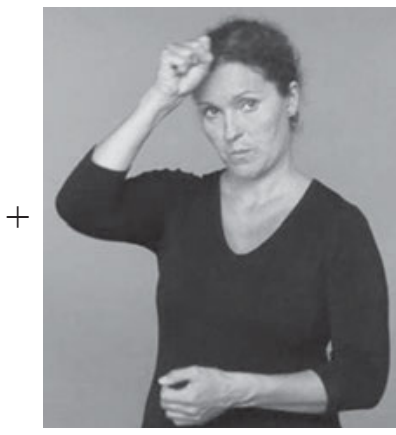

(d) BOY

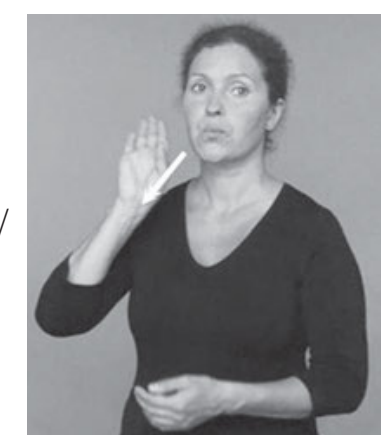

(e) GIRL

Figure 27. EVK core family terms: DAUGHTER, SON, SIBLING, BOY and GIRL

While MAN (figure 28b) and WOMAN (figure 28c) are gendered lexicalised signs, the signs for spouse (figure 28a) as well as fiancé and fiancée are non-gendered. Similarly to the Estonian language, where words mees [man, husband] and naine [woman, wife] are actually used also in the meaning of 
wife and husband, the general terms MAN and WOMAN may also be used to denote gendered spouse.

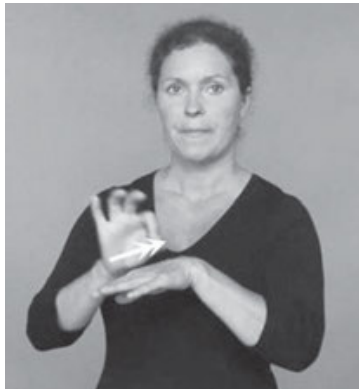

(a) SPOUSE

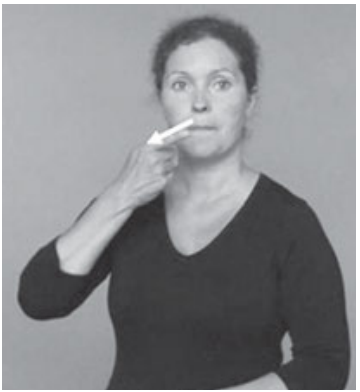

(b) MAN

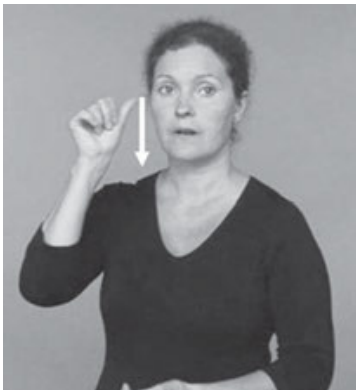

(c) WOMAN

Figure 28. EVK core family terms: SPOUSE, MAN and WOMAN

Age differences among the family members can only be described through complex descriptions (see examples 17 and 18).

(17) $\mathrm{BOY}+$ SIBLING OLD

older brother

(18) GIRL+SIBLING SMALL

younger sister

Non-core family members are indicated by lexical signs or compounds (OLD+MOTHER(figure29a+b), OLD+FATHER(figure29a+c),FEMALE+RELATIVE, MALE+RELATIVE) without any distinction in maternal and paternal relations. If needed to indicate maternal or paternal grandparents, complicated compounds MOTHER OWN FATHER or FATHER OWN FATHER etc are used. There are also signs for non-gendered same generation cousin and fiancél fiancée.

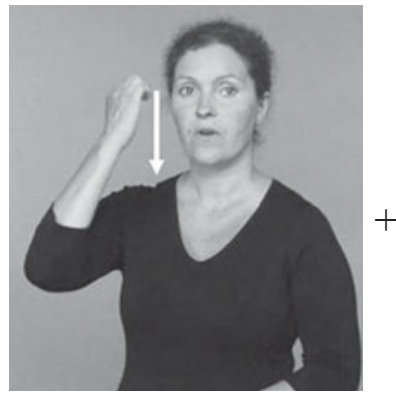

(a) OLD

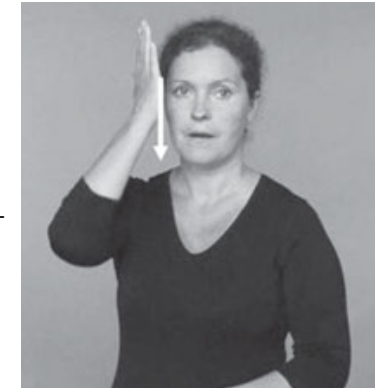

(b) MOTHER

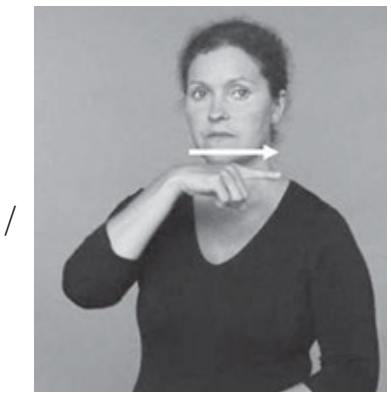

(c) FATHER

Figure 29. EVK non-core family terms: GRANDMOTHER and GRANDFATHER 
It is interesting to note that the signs used to denote siblings, aunts/uncles and cousins are all produced with the same handshape in the same location but with a different movement. The sign SIBLING (figure 30a) has the same handshape as relatives in general but with the movement pattern from sign BESIDE, while COUSIN and UNCLE/AUNT (figure 30b) pattern with relatives in general sharing the same movement.

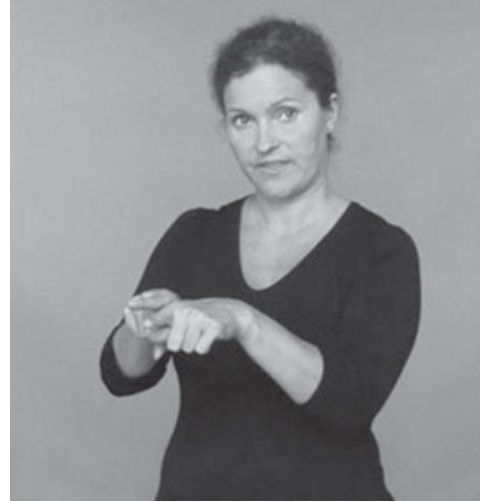

(a) SIBLING

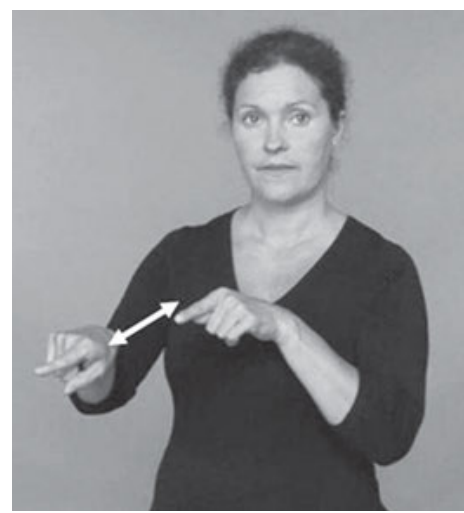

(b) RELATIVE

Figure 30. EVK family terms: SIBLING and RELATIVE

For grandchildren a compound CHILD+SMALLER_CHILD (figure 31) is used, but it is also possible to use more complex descriptions like DAUGHTER CHILD or DAUGHTER OWN SON etc. The latter are however not lexicalised terms.

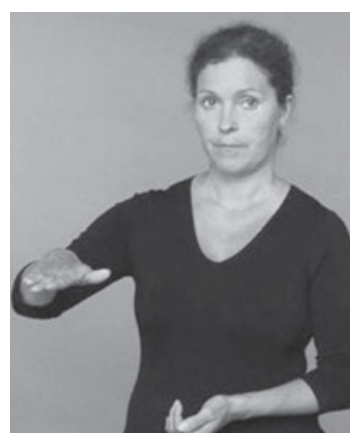

(a) CHILD

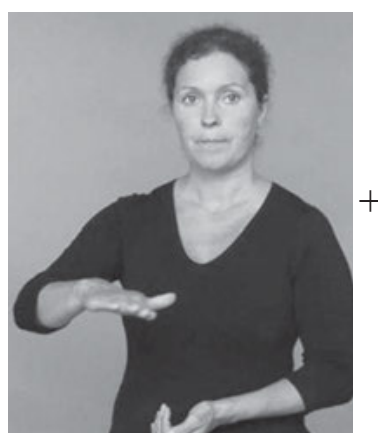

(b) CHILD +

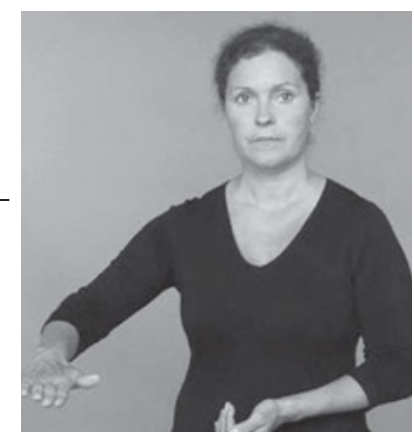

(c) SMALLER_CHILD

Figure 31. EVK family terms: CHILD and GRANDCHILD

Signs denoting extended family members in EVK are mainly loans from spoken Estonian. Father-in-law and mother-in-law are two of the very rare 
fingerspelled signs in ESL. Signs ä-mm [mother-in-law] and ä-i [father-in-law] are short enough words in Estonian and easy to fingerspell. Of course the longer explanations like HUSBAND OWN MOTHER or WIFE OWN FATHER etc may also be observed. The only possibility to construct generic terms parent-in-law or sibling-in-law are complex combinations to describe the family relations.

Similarly to the compounds in spoken Estonian, half-siblings are referred to by the lexicalised compounds HALF+SIBLING, HALF+SIBLING+GIRL and HALF+SIBLING+BOY. There are also translated compounds for stepfather and stepmother as well as stepparents.

Reduplication of the kinship terms is used for three different purposes. First, the signs formed in the neutral signing space away from the body may be reduplicated for pluralisation (SIBLING+++ for brothers and sisters, CHILD+++ for children). In both cases the signs are reduplicated in different locations. To form plurals of the signs that make contact with the face or body (MOTHER, FATHER, SON, DAUGHTER etc) an attributive sign CHILD or PERSON is used for reduplication (for example MOTHER PERSON+++ [mothers] or SON CHILD+++ [sons]).

Secondly, accompanied with a facial expression, fast reduplication of a sign formed in contact with the face or body (MOTHER, FATHER) may have diminutive function. In this way the signs MUMMY and DADDY are derived from MOTHER and FATHER. These signs do not refer only to ego's parents but can be used to denote any parent.

Reduplication combined with spatial modification of a sign articulated in the neutral space (GRANDCHILDREN, figure 31) or slow reduplication (MOTHER + for maternal grandmother or FATHER + for paternal grandfather) may also be used to show the generation level. The latter can however be rather seen as compound of two signs MOTHER and MOTHER without any spatial modification (or FATHER and FATHER) than reduplication as this is also the structure used to form the signs for other grandparents (FATHER MOTHER Or FATHER OWN MOTHER and MOTHER FATHER Or FATHER OWN MOTHER). The origin of these constructions is the influence from spoken Estonian where the same compounds are used to denote paternal or maternal grandparents. Spatial modification to indicate age can only be seen in the reduplicated sign GRANDCHILD where the first part of the sign is formed higher than the last part of the reduplicated sign (figure $31 \mathrm{~b}, \mathrm{c}$ ).

Age differences are usually not reflected in the lexicalised signs in EVK although in the sequential constructions with modifiers like YOUNG, OLD, SMALL or BIG (younger, older, smaller or bigger) SIBLING the sign SIBLING 
is formed lower or higher in the signing space respectively. The difference is only comprehensible in comparison.

As mentioned above, a linker sign OWN may be seen in many constructions explaining family relations but these are not lexicalised signs in EVK.

The influence from spoken Estonian in kinship terms may be seen in fingerspelled signs, mouthing and direct translations of the compounds used in Estonian. Although there are many initialised signs, fingerspelled signs are exceptionally rare in EVK. The two rare examples are gendered terms for parents-in-law - fingerspelled Estonian words ä-mm (mother-in-law, figure 32a)) and ä-i (father-in-law, figure 32b) are fully lexicalised signs and the only terms for the parents-in-law in EVK.

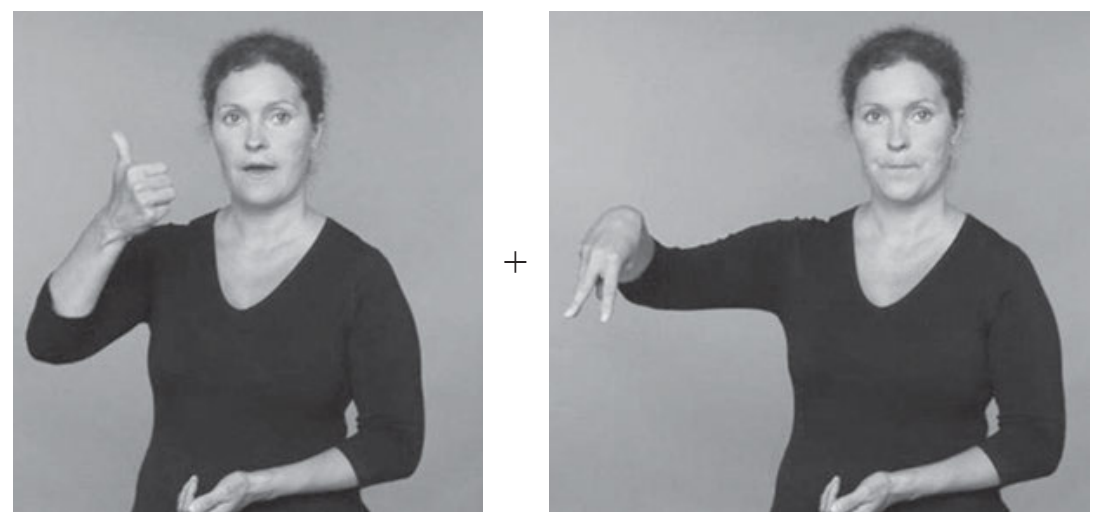

(a) MOTHER-IN-LAW

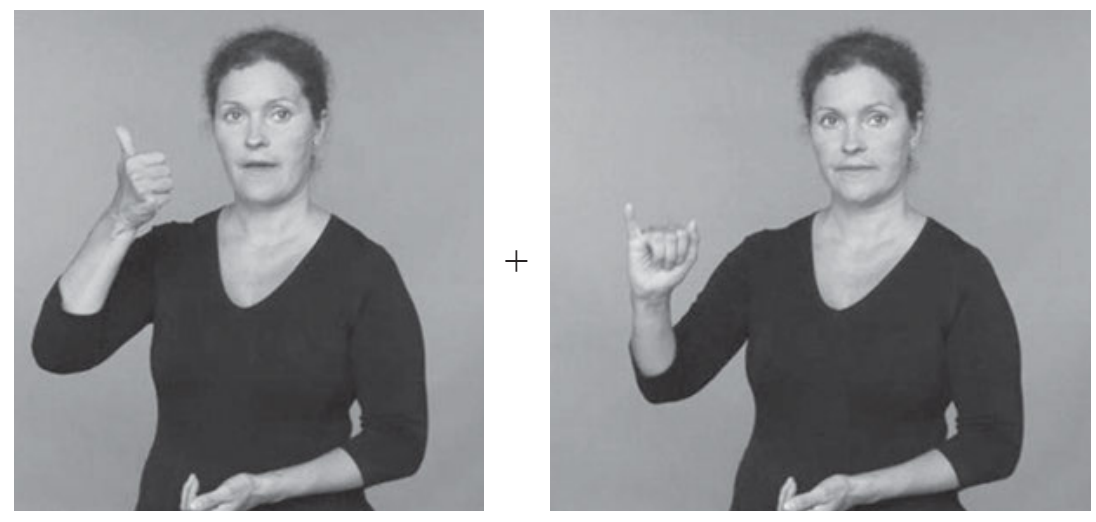

(b) FATHER-IN-LAW

Figure 32. EVK family terms: MOTHER_IN_LAW and FATHER_IN_LAW 
To specify the meaning of the generic terms in EVK, mouthing of the more specific Estonian term accompanies the EVK sign. This may be observed in colour terms as well as kinship terms. The signs SIBLING and AUNT/UNCLE may be used without the attributes BOY or GIRL, WOMAN or MAN but accompanied with mouthing the respective Estonian word instead to distinguish gender.

There are also some compounds among the kinship terms which are clearly direct translations of the Estonian compounds. Terms for gendered grandparents OLD + MOTHER and OLD + FATHER, although fully lexicalised in EVK, are exact translations of the Estonian words vanaisa (old+father) and vanaema (old+mother). The same is probably the case with the expression of parents - although MOTHER/FATHER is more frequent in EVK, there is also a reduplicated sign OLD, a translation of Estonian word vanemad (plural form of older) to denote non-gendered parents similarly to spoken Estonian.

Besides the reduplicated sign OLD, SIBLING without the attributive sign GIRL or BOY or respective mouthing also means same in EVK and AUNT/ UNCLE without the attributes is a generic term for relative.

Diagrammatic description of the kinship terms through pointing and tracing might be used while describing family relations but they do not have conventional lexicalised meaning. While pointing or tracing is used, it is done with the index finger or an open hand, and the handshape used refers neither to gender nor age.

Comparing the kinship terms in EVK and Estonian it may be seen that while the gender distinction is secondary in some EVK terms (SIBLING, AUNT/UNCLE) the respective Estonian terms differentiate gender. There are also terms where gender distinction is secondary in both languages (cousin, spouse). As is characteristic of sign language, the list of two or three typical members of the group is preferred to a generic simple term (MOTHER +FATHER instead of the translated loan from Estonian for parents). The influence from spoken Estonian might be seen in sequential compounds describing extended family relations (grandparents, grandchildren).

Following the formation of the EVK terms in the analysed three domains it may be seen that while for the colour terms the main strategy of sign creation has probably been derivation from pointing to the representations of the respective colours (lips or cheek for red and pink, sleeves for white or beard for gray) and extension of meaning (coffee to brown, Christmas to green, or clean to white), the numerals are mainly iconic representations of the respective quantities accompanied with a certain movement pattern. The number of arbitrary native signs is largest among kinship terms while the influence 
from spoken Estonian may be seen in initialised colour terms (orange, purple and beige) and fingerspelled signs among kinship terms (mother-in-law and father-in-law) as well as translated compounds like grandmother, grandfather, stepfather, stepmother etc. Influence from Russian SL is in the current study only observed in the domain of colour terms, but according to earlier studies (Taniroo 2007) it is evident that the similarities are common also in other domains.

Although the influence from Estonian may be observed in EVK in many aspects and there are a number of loans from Russian SL used in EVK, it may be seen that EVK has developed a rich lexicon in the analyzed domains, and among the colour terms, nine categories out of eleven are denoted with a salient basic term.

\section{Acknowledgements}

The drawings in the chapter were made by Ivo Kaunissaare, photographs by Triin Jõeveer, the signers are Maret Õun, Riina Kuusk and Riho Kurg. The pictures are taken from the Estonian - Estonian Sign Language online dictionary, compiled on the basis of the Basic Estonian Dictionary.

\section{References}

Berlin, Brent, and Paul Kay. 1969. Basic Color Terms, Their Universality and Evolution. University of California Press. Berkeley.

Davies, Ian R. L., and Greville G. Corbett. 1994. The basic color terms of Russian. In Linguistics 32, pp 65-89.

Davies, Ian R. L., and Greville G. Corbett. 1995. A practical field method for identifying probable basic colour terms. In Languages of the World 9, pp 25-36.

Davies, Ian R. L., Corbett, Greville G., and Margalef, José Bayo. 1995. Colour terms in Catalan: An investigation of eighty informants, concentrating on the purple and blue regions. In Transactions of the Philological Society 93, pp 17-49.

Fletcher, Robert. 1998. The City University Colour Vision Test. 3rd ed. London: Keeler.

Hollman, Liivi. 2010. Basic Color Terms in Estonian Sign Language. University of Tartu.

Kivisild, Kai, and Regina Toom. 1990. Eesti kristlikud viiped. [Estonian Christian Signs]. Tartu, Stockholm. 
Miljan, Merilin. 2000. The Noun Phrase in Estonian Sign Language from the Typological Perspective. BA Thesis. Estonian Institute of Humanities. Tallinn. Miljan, Merilin. 2001. Adjectival Modification in Estonian and Estonian Sign Language. In Estonian Typological Studies V. Publications of the Department of Estonian of the University of Tartu 18. Tartu, pp 169-188.

Miljan, Merilin. 2003. Number in Estonian Sign Language. In Trames 2003, $7(57 / 52), 3$, pp 293-223.

Paales, Liina. 2002. Isiku- ja kohanimed eesti kurtide märgipärimuses. [Name Signs for Persons and Places in Estonian Deaf Folklore] In Lemmeleht. Pro Folkloristika IX. Eesti Kirjandusmuusum. Tartu, pp 154-167.

Paales, Liina. 2011. Kurtide nimepärimuse aspekte: puudelisuse ja kurdiksolemise folkloristlik uurimus. [Aspects of Deaf name lore: A folkloristic study of disability and Deafhood]. University of Tartu.

Sutrop, Urmas. 2000. The Basic Color Terms of Estonian. In Trames, 4(54/49), 1, pp 143-168.

Sutrop, Urmas. 2001. List Task and a Cognitive Salience Index. In Field Methods, Vol.13, No.3, pp 263-276.

Sutrop, Urmas. 2002. The Vocabulary of Sense Perception in Estonian: Structure and History. Opuscula Fenno-Ugrica Gottingensia. Frankfurt am Main: Peter Lang.

Zeshan, Ulrike. 2005. Sign Languages. In The World Atlas of Language Structures. Oxford University Press, pp 558-559.

Taniroo, Liisi. 2007. Eesti viibete võrdlus vene viibetega Swdesh 200 nimekirja alusel. [Comparison of EVK signs to Russian Sign Language signs according to Swadesh word list 200]. BA Thesis. University of Tartu.

Toom, Regina. 1988. Kõnelevad Käed. Eesti viipekeele sõnaraamat. [Talking Hands. Estonian Sign Language Dictionary]. University of Tartu, Estonian Association of the Deaf.

Toom, Regina. 1990. Abimaterjale eesti viipekeele omandamiseks. [Guidelines for learners of Estonian Sign Language]. University of Tartu, Estonian Association of the Deaf.

Wheatley, Mark, and Pabsch Annika. 2012. Sign Language Legislation in the European Union. European Union of the Deaf, Brussels. 